\title{
Enhanced Hole Transport in Ternary Blend Polymer Solar Cells
}

\author{
$\operatorname{AUTHOR}(\mathrm{S})$ :
}

Midori, Koshiro; Fukuhara, Tomohiro; Tamai, Yasunari; Kim, Do Hyung; Ohkita, Hideo

\section{CITATION:}

Midori, Koshiro ... [et al]. Enhanced Hole Transport in Ternary Blend Polymer Solar Cells. ChemPhysChem 2019, 20(20): 2683-2688

\section{ISSUE DATE:}

2019-10-16

URL:

http://hdl.handle.net/2433/244392

\section{RIGHT:}

This is the peer reviewed version of the following article: K. Midori, T. Fukuhara, Y. Tamai, H. Do Kim, H. Ohkita, ChemPhysChem 2019, 20, 2683., which has been published in final form at https://doi.org/10.1002/cphc.201900343. This article may be used for non-commercial purposes in accordance with Wiley Terms and Conditions for Use of SelfArchived Versions.; The full-text file will be made open to the public on 16 October 2020 in accordance with publisher's 'Terms and Conditions for Self-Archiving'.; この論文は出版社版でありません。引用の際には出版社版をご確認ご利用 ください。; This is not the published version. Please cite only the published version. 


\title{
Enhanced Hole Transport in Ternary Blend Polymer Solar Cells
}

\author{
Koshiro Midori, ${ }^{[a]}$ Tomohiro Fukuhara, ${ }^{[a]}$ Yasunari Tamai, ${ }^{[a, b]}$ Hyung Do Kim, ${ }^{[a]}$ and Hideo Ohkita*[a]
}

\begin{abstract}
Recently, ternary blend polymer solar cells have attracted great attention to improve a short-circuit current density (JSC) effectively because complementary absorption bands can harvest the solar light over a wide wavelength range from visible to near-IR region. Interestingly, some ternary blend solar cells have shown improvements not only in $J_{S C}$ but also in a fill factor (FF). Previously, we also reported that a ternary blend solar cell based on a lowbandgap polymer PTB7-Th, a wide-bandgap polymer PDCBT, and a fullerene derivative PCBM exhibited a FF higher than that of their binary analogues. Herein, we study charge transport in PTB7Th/PDCBT/PCBM ternary blend film to address the origin of the improvement in FF. As a result, we found that hole polarons are located in PTB7-Th domains and their mobility is enhanced in the ternary blend film.
\end{abstract}

\section{Introduction}

Polymer solar cells have made rapid progress in the last two decades. ${ }^{1-10}$ Currently, a power conversion efficiency has exceeded $15 \%{ }^{11}$ for single junction solar cells and $17 \%{ }^{12}$ for tandem solar cells. These remarkable improvements are partly due to an efficient light-harvesting over a wide wavelength range from visible to near-IR region. It has been difficult to achieve such a wide-range light harvesting by using conventional polymer solar cells based on binary blends of a conjugated polymer and a fullerene derivative, because most organic materials have limited absorption bandwidths typically as narrow as $200 \mathrm{~nm}$ at most and fullerene derivatives have negligible absorption bands in the visible region. On the other hand, ternary blend polymer solar cells can harvest the solar light over a wide wavelength range from visible to near-IR region because of complementary absorption bands and therefore have attracted great attention as a simple approach to improving the short-circuit current density $\left(J_{\text {sc }}\right)$ effectively. ${ }^{13-16}$

A fill factor (FF) is a measure of charge transport in solar cells. For most ternary blend polymer solar cells, FF is comparable to or lower than that of binary blend counterparts because the third

\footnotetext{
[a] Mr K. Midori, Mr T. Fukuhara, Dr Y. Tamai, Dr H. D. Kim, Prof H Ohkita

Department of Polymer Chemistry

Graduate School of Engineering, Kyoto University

Katsura, Nishikyo-ku, Kyoto 615-8510, Japan

E-mail: ohkita@photo.polym.kyoto-u.ac.jp

[b] Dr Y. Tamai

PRESTO

Japan Science and Technology Agency (JST)

4-1-8 Honcho, Kawaguchi, Saitama 332-0012, Japan
}

material is likely to hinder charge transport. ${ }^{17-22}$ Interestingly, however, recent studies have shown that some ternary blend polymer solar cells exhibit a distinctly larger FF than binary blend solar cells. ${ }^{23,24}$ We also have reported the improvement in FF for a ternary blend polymer solar cell based on poly[4,8-bis(5-(2ethylhexyl)thiophen-2-yl)benzo[1,2-b:4,5-b']dithiophene-co-3fluorothieno[3,4-b]thiophene-2-carboxylate] (PTB7-Th), poly[5,5' bis(2-butyloctyl)-(2,2'-bithiophene)-4,4'-dicarboxylate-alt-5,5' 2,2'-bithiophene] (PDCBT), and [6,6]-phenyl- $\mathrm{C}_{61}$-butyric acid methyl ester (PCBM) as shown in Figure 1. ${ }^{25}$ As a result, we found that the optimized active layer is as thick as $280 \mathrm{~nm}$ for PTB7-Th/PDCBT/PCBM ternary blend solar cell while it is as thin as $130 \mathrm{~nm}$ for PTB7-Th/PCBM binary blend solar cell.

Herein, we study hole transport in the PTB7-Th/PDCBT/PCBM ternary blend to address the origin of the improvement in FF. First, we measured transient absorption of ternary blend film to discuss the location of hole polarons in ternary blends. Next, we estimated hole mobility in ternary and binary blend films by measuring space-charge limited current (SCLC). Finally, we discuss the relationship between the improved charge transport and ordering of polymer chains on the basis of the absorption spectra of ternary blend film. a)

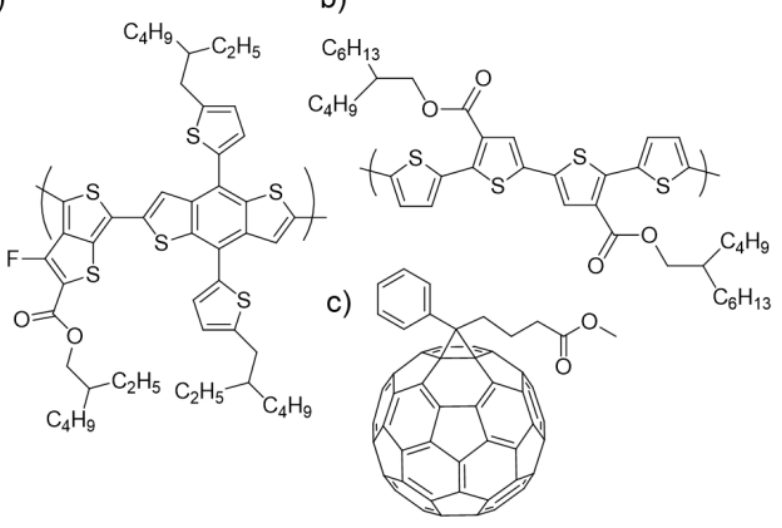

Figure 1. Chemical structures of materials employed in this study: a) PTB7-Th, b) PDCBT, and c) PCBM.

\section{Results and Discussion}

Figure 2 shows the absorption spectra of PTB7-Th, PDCBT, and PCBM neat films. As shown in the figure, PCBM has a large absorption band at around $350 \mathrm{~nm}$ in the UV region, a widebandgap polymer PDCBT has an absorption band at around 550 $\mathrm{nm}$ in the visible region, and a low-bandgap polymer PTB7-Th has 
an absorption band at around $700 \mathrm{~nm}$ in the near-IR region. In other words, each absorption band complementally covers the wide wavelength range from 300 to $800 \mathrm{~nm}$. Consequently, PTB7-Th/PDCBT/PCBM ternary blend polymer solar cells exhibited an improved $J_{\mathrm{SC}}$ as large as $\sim 20 \mathrm{~mA} \mathrm{~cm}^{-2}$. Interestingly, as summarized in Table 1,25 FF was also improved from 0.52 for PTB7-Th/PCBM binary blend device to 0.60 for PTB7Th/PDCBT/PCBM ternary blend device with a thick active layer. The photovoltaic characteristics are shown in Figure S1 (see the Supporting Information). A recent study has also shown similar improvements both in $J_{S C}$ and FF for PTB7-Th/PDCBT/PCBM ternary blend polymer solar cells. ${ }^{26}$

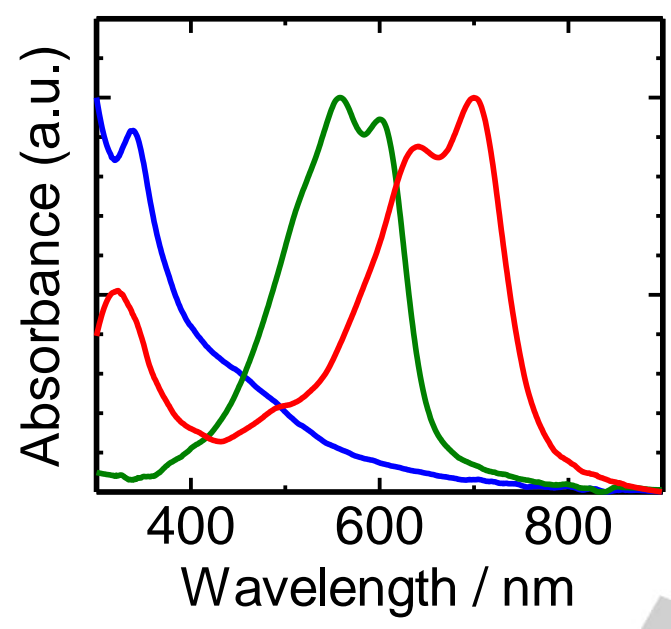

Figure 2. Normalized absorption spectra of PTB7-Th (red line), PDCBT (green line), and PCBM (blue line) neat films.

Table 1. Photovoltaic parameters of binary and ternary blend solar cells.

\begin{tabular}{ccccc}
\hline Devices & $J_{S C}\left(\mathrm{~mA} \mathrm{~cm}^{-2}\right)$ & $V_{\text {OC }}(\mathrm{V})$ & FF & PCE (\%) \\
\hline binary $^{\mathrm{a}}$ & 18.0 & 0.799 & 0.520 & 7.48 \\
ternary $^{\mathrm{b}}$ & 19.4 & 0.762 & 0.604 & 8.93 \\
\hline
\end{tabular}

a PTB7-Th/PCBM (1/1.5 w/w) binary blend solar cell

${ }^{b}$ PTB7-Th/PDCBT/PCBM $(0.75 / 0.25 / 1.5 \mathrm{w} / \mathrm{w})$ ternary blend solar cell

Reproduced with permission from Ref. 25. Copyright 2018 The Chemical Society of Japan.

In order to assign hole polarons in PTB7-Th/PDCBT/PCBM ternary blends, we measured transient absorption spectra of binary and ternary blend films. Figure 3 shows the transient absorption spectra of each binary blend film. For PTB7-Th/PCBM blends, an absorption band was observed at around $1150 \mathrm{~nm}$ with a broad shoulder at $800-1000 \mathrm{~nm}$ and a negative signal at around $700 \mathrm{~nm}$. As reported previously, hole polarons of PTB7-Th exhibited an absorption at around $1150 \mathrm{~nm}^{27}$ We therefore ascribed the absorption spectrum above $800 \mathrm{~nm}$ to PTB7-Th hole polarons. The wavelength of the negative signal is consistent with the absorption of PTB7-Th as shown in Figure 2. We therefore ascribed the negative signal to the ground-state photobleaching of PTB7-Th. Note that a small absorption shoulder at around $1300 \mathrm{~nm}$ observed at an early time stage is assigned to triplet excitons of PTB7-Th, which is formed by bimolecular charge recombination as reported previously. ${ }^{27}$ For PDCBT/PCBM blends, a broad absorption band was observed from 600 to 1000 $\mathrm{nm}$ with a peak at around $950 \mathrm{~nm}$. This spectrum is similar to that of P3HT hole polarons as reported previously. ${ }^{28,29}$ We therefore ascribed this broad absorption to PDCBT hole polarons. Both decays were well fitted with an empirical power-law given by the equation 1.

$$
n(t)=\frac{n_{0}}{(1+a t)^{\alpha}}
$$

Here, $n(t)$ is the charge density at a time $t, n_{0}$ is the initial charge density at a time $t=0, a$ and $\alpha$ and are kinetic parameters. This power-law decay dynamics is characteristic of bimolecular charge recombination in disordered materials with exponential energetic tails. $^{30,31}$ Thus, the power-law decay is also consistent with our assignments of hole polarons observed for PTB7-Th/PCBM and PDCBT/PCBM blend films.

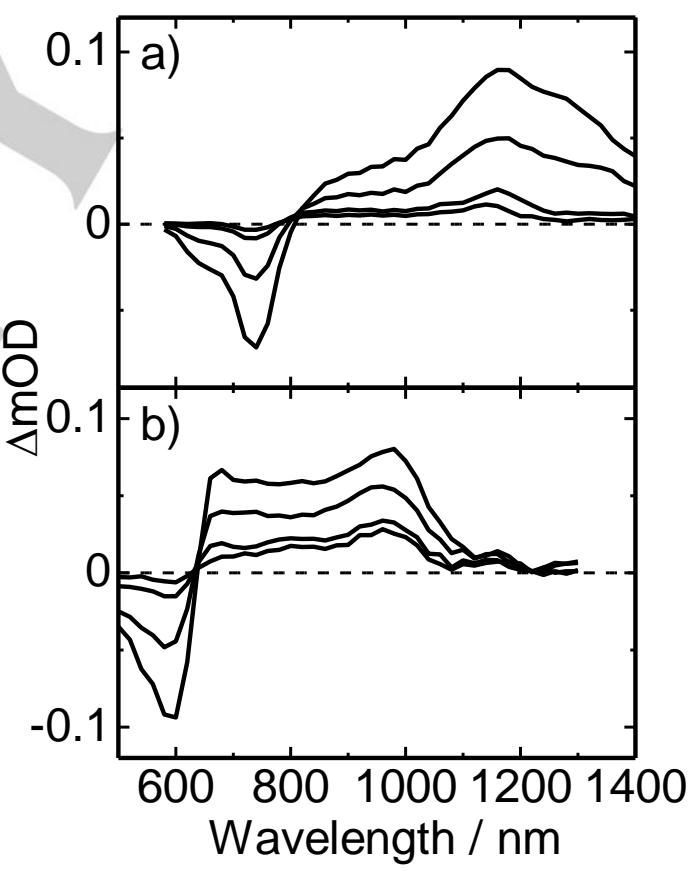

Figure 3. Transient absorption spectra of each binary blend film: a) PTB7 Th/PCBM (1/2 w/w) excited at $532 \mathrm{~nm}$ and b) PDCBT/PCBM (1/1 w/w) excited at $500 \mathrm{~nm}$. The delay time is about $1,2,5$, and $10 \mu$ s after the laser excitation from top to bottom in each panel.

Figure 4 shows the transient absorption spectrum of PTB7Th/PDCBT/PCBM ternary blend film upon selective photoexcitation of PDCBT. Considering the selective excitation, transient absorption of PDCBT hole polarons would be observed at around $950 \mathrm{~nm}$. However, this is not the case. As shown in the figure, the absorption spectrum was almost the same as that 
observed for PTB7-Th/PCBM rather than PDCBT/PCBM. We estimated that more than $90 \%$ of hole polarons are located not in PDCBT but in PTB7-Th domains in PTB7-Th/PDCBT/PCBM ternary blend film on the basis of spectral simulation (see Figure S2 in the Supporting Information). We therefore conclude that PTB7-Th domains are hole transport channels and PTB7-Th hole polarons serve as a hole carrier in PTB7-Th/PDCBT/PCBM ternary blend film.

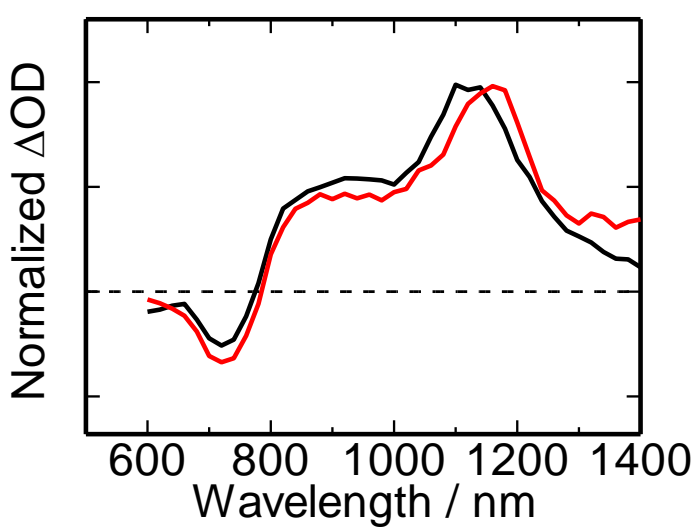

Figure 4. Transient absorption spectra of PTB7-Th/PDCBT/PCBM (1/1/3 w/w) ternary blend (black line) and PTB7-Th/PCBM (1/2 w/w) binary blend (red line) films excited at $532 \mathrm{~nm}$. The delay time is about $5 \mu \mathrm{s}$ after the laser excitation.

We thus discuss why hole polarons were predominantly located in PTB7-Th domains even though PDCBT was selectively excited. Here, we propose two possible explanations. The first one is a Förster resonance energy transfer from PDCBT to PTB7Th. As shown in Figure 5, the PDCBT emission was significantly quenched for PTB7-Th/PDCBT binary blend film in comparison with that for PDCBT neat film. Instead, the PTB7-Th emission was much enhanced for PTB7-Th/PDCBT blend film in comparison with that for PTB7-Th neat film. These findings are indicative of the energy transfer from PDCBT to PTB7-Th. From the spectral overlap between the PDCBT emission and PTB7-Th absorption spectra as shown in Figure S3, the Förster radius was evaluated to be as large as $3.6 \mathrm{~nm}$ assuming randomly-oriented point-dipoles. Here, photoluminescence quantum yield of PDCBT was evaluated to be 0.03 relative to that of a perylenediimide derivative. ${ }^{32}$ An effective refractive index was assumed to be 1.4. ${ }^{33}$ Such efficient long-range energy transfer from PDCBT to PTB7-Th would be in competition with rapid charge generation at an interface of PDCBT/PCBM. Indeed, a highly efficient energy transfer has been reported for polymer/polymer blends. ${ }^{37-39}$ Very recently, a fast energy transfer from PDCBT to PTB7-Th has been reported for PTB7-Th/PDCBT/PCBM ternary blend. ${ }^{26}$ The second one is hole transfer from PDCBT to PTB7-Th domains as reported for other blends. ${ }^{28,37}$ As shown in Figure 6, the HOMO energy level was evaluated to be $-5.0 \mathrm{eV}$ for PTB7-Th and -5.1 $\mathrm{eV}$ for PDCBT films by the photoelectron emission yield spectroscopy. This suggests that hole polarons are thermodynamically more stable in PTB7-Th rather than in PDCBT domains. Assuming the Boltzmann distribution, the population of hole polarons are about 50 times larger in PTB7-Th than in PDCBT domains. In other words, $98 \%$ of hole polarons are spontaneously located in PTB7-Th domains with a shallower HOMO level at a thermal equilibrium.

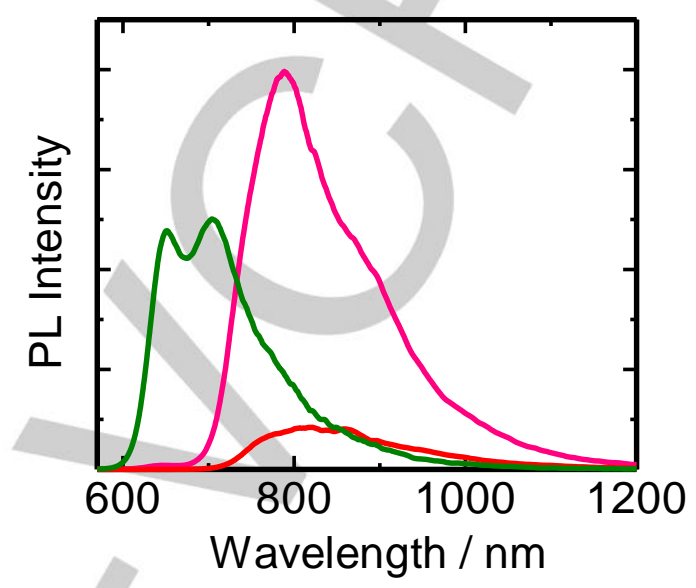

Figure 5. Photoluminescence spectra of PTB7-Th/PDCBT $(1 / 4 \mathrm{w} / \mathrm{w})$ binary blend (purple line), PDCBT neat (green line), and PTB7-Th neat (red line). The $\mathrm{PL}$ intensity was corrected for variation in the absorption at an excitation wavelength of $520 \mathrm{~nm}$.

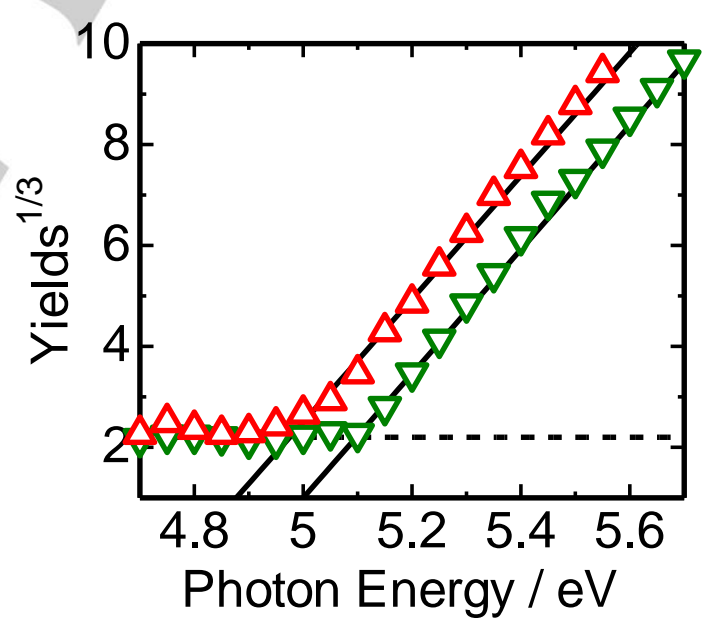

Figure 6. Photoelectron emission yield spectra of PTB7-Th (red triangles) and PDCBT (green inverted triangles) neat films.

We next evaluated the hole mobility of polymer neat and blend films by measuring SCLC for hole only devices with a layered structure of ITO/PEDOT:PSS/polymer/Au. The hole mobility is given by the Mott-Gurney equation ${ }^{41}$

$$
J=\frac{9}{8} \varepsilon_{0} \varepsilon_{\mathrm{r}} \mu \frac{V^{2}}{L^{3}}
$$

where $\varepsilon_{0}$ is the permittivity of vacuum, $\varepsilon_{r}$ is the relative dielectric constant of the material $\left(\varepsilon_{r}=3\right), \mu$ is the charge carrier mobility, and $L$ is the active layer thickness. As summarized in Table 2, 
the hole mobility in binary blend films was comparable to or larger than that in neat films. Interestingly, the hole mobility was as large as $6.3 \times 10^{-4} \mathrm{~cm}^{2} \mathrm{~V}^{-1} \mathrm{~s}^{-1}$ for PTB7-Th/PDCBT/PCBM ternary blend film even though the volume fraction of PTB7-Th was reduced to $30 \%$ compared to that of neat film. As shown in Figure 7, trap filling region was observed from 0.1 to $1 \mathrm{~V}$ for both PTB7Th and PDCBT neat films but not observed for ternary blend film. This finding is consistent with the improved hole mobility in ternary blend film, suggesting that PTB7-Th chains diluted in other materials exhibit improved hole transport properties. Similar improvements have been reported for blends of a semiconducting polymer that is mixed with a high-bandgap polymer. ${ }^{39-41}$ In these diluted blends, the charge transport was improved or comparable to that in neat films. Thus, such dilution would be versatile approach to improving charge transport.

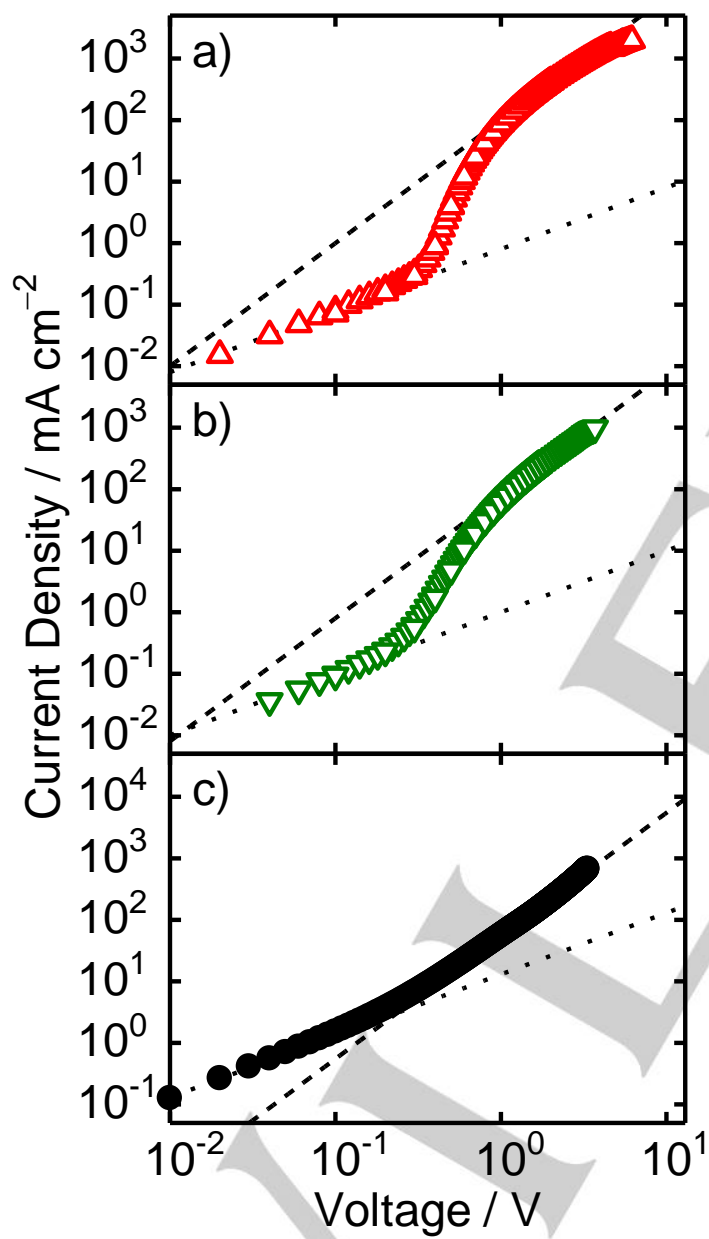

Figure 7. Log-log plots of current density against voltage measured for a) PTB7-Th neat film, b) PDCBT neat film, and c) PTB7-Th/PDCBT/PCBM $(0.75 / 0.25 / 1.5 \mathrm{w} / \mathrm{w})$ ternary blend film. The broken lines represent a fitting curve with the Mott-Gurney equation. The dotted lines represent a fitting curve with a slope of unity.

Table 2. Hole mobility in each film.

Samples Hole mobility $\left(\mathrm{cm}^{2} \mathrm{~V}^{-1} \mathrm{~s}^{-1}\right)$

\begin{tabular}{cc}
\hline PTB7-Th & $2.8 \times 10^{-4}$ \\
PDCBT & $1.3 \times 10^{-4}$ \\
PTB7-Th/PCBM & $2.4 \times 10^{-4}$ \\
PDCBT/PCBM & $2.7 \times 10^{-4}$ \\
PTB7-Th/PDCBT/PCBM & $6.3 \times 10^{-4}$ \\
\hline
\end{tabular}

Finally, we discuss the origin of the increased hole mobility in ternary blend film by comparing the absorption spectra of PTB7Th neat film with that of ternary blend film. For comparison, the absorption spectra of PDCBT and PCBM were subtracted from the absorption spectrum of PTB7-Th/PDCBT/PCBM ternary blend film. The details of the spectral resolution are described in the Supporting Information (Figure S4). As shown in Figure 8, the ratio of the $0-0$ to $0-1$ vibronic absorption bands of PTB7-Th $A_{0-}$ ${ }_{0} / A_{0-1}$ was larger in the ternary blend than in the PTB7-Th neat film. The increase in $A_{0-0} / A_{0-1}$ indicates that the backbone of PTB7-Th becomes more ordered structures in ternary blend film. ${ }^{42,43}$ Such an improvement in ordering of polymer chains has been reported for a crystalline polymer P3HT blended with polystyrene. ${ }^{41}$ We therefore conclude that the improvement in hole transport is due to higher ordering of PTB7-Th chains in ternary blend film.

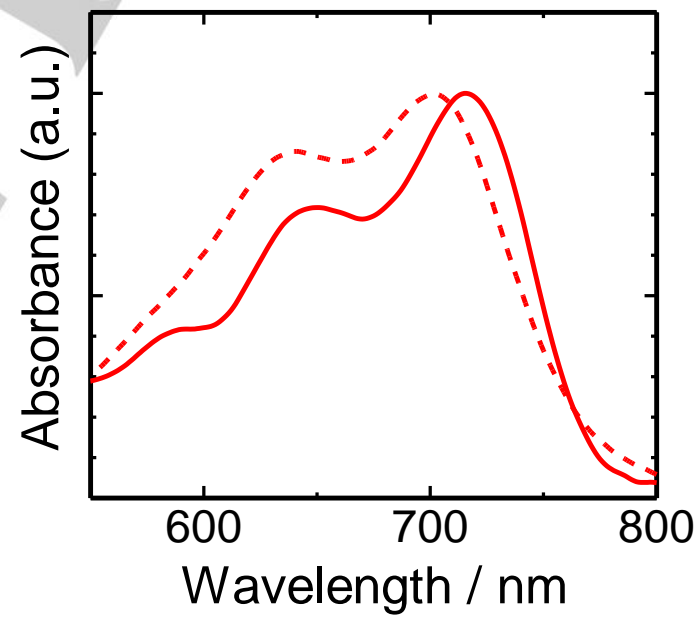

Figure 8. Absorption spectra of PTB7-Th in the neat film (red broken line) and in the PTB7-Th/PDCBT/PCBM $(0.75 / 0.25 / 1.5 \mathrm{w} / \mathrm{w}$ ) ternary blend film (red solid line). The PTB7-Th spectrum in ternary blend film was obtained by subtracting PDCBT and PCBM absorption spectra from the original spectrum. The absorption was normalized at the $A_{0-0}$ transition peak.

\section{Conclusions}

The hole transport in PTB7-Th/PDCBT/PCBM ternary blend film was studied to discuss the improvement in FF compared to those for binary counterparts. For PTB7-Th/PDCBT/PCBM blend, we found that hole polarons are located in PTB7-Th domains even though PDCBT was selectively excited, because of energy 
transfer and/or hole transfer from PDCBT to PTB7-Th. The hole mobility was increased in PTB7-Th/PDCBT/PCBM blend compared to that of PTB7-Th/PCBM blend. More ordered backbone of PTB7-Th leads to an efficient hole carrier transport. Our work reveals hole transport property can be enhanced by blending other materials, which is a key to more efficient ternary blend solar cells.

\section{Experimental Section}

Sample Preparation. PTB7-Th and PDCBT were purchased from 1Material. PCBM was purchased from Frontier Carbon. Films were spincoated onto quartz substrates from a chlorobenzene solution with an additive of 1,8-diiodooctane (DIO) (3 vol\%) for PTB7-Th/PCBM and PTB7Th/PDCBT/PCBM blends. For hole-only devices, the structure of glass/ITO/PEDOT:PSS/polymer/Au was used. PEDOT:PSS was spincoated onto ITO and thermally annealed at $140^{\circ} \mathrm{C}$ for $10 \mathrm{~min}$. The polymer layers were prepared on the ITO/PEDOT:PSS substrate by spin-coating from a chlorobenzene solution. The Au electrode was deposited on top of the polymer layer by vacuum evaporation.

Absorption and Photoluminescence Spectroscopy. The absorption spectra were measured with a spectrophotometer (Hitachi, U-4100). The photoluminescence spectra were measured with a spectrophotometer (Horiba Jobin Yvon, NanoLog).

Photoelectron Emission Yield Spectroscopy. The HOMO level of donor polymers was measured with a photoelectron emission yield spectrometer (Riken Keiki, AC-3E).

Transient Absorption Spectroscopy. In the microsecond transient absorption measurement, a dye laser pumped by a nitrogen laser (Photon Technology International, GL-301, GL-3300) or an Nd:YAG laser (Elforlight, SPOT20-532) was used as an excitation source. A tungsten lamp (Thermo-Oriel, 66997) was used as a probe light source. Details have been described elsewhere. ${ }^{44}$

Space-Charge-Limited Current (SCLC). The SCLC measurements were performed on the hole-only devices. The current-voltage characteristics were analyzed using the Mott-Gurney equation.

\section{Acknowledgments}

This work was partly supported by JST ALCA program Grant Number JPMJAL1404 and JST PRESTO program Grant Number JPMJPR1874, and JSPS KAKENHI Grant Number 18J20587, Japan.

Keywords: polymer solar cell • fill factor $•$ hole transport • ternary blend $\cdot$ dilution

1. S. Shaheen, C. Brabec, N. Sariciftci, F. Padinger, T. Fromherz, J. Hummelen, Appl. Phys. Lett. 2001, 78, 841-843.

2. F. Padinger, R. Rittberger, N. Sariciftci, Adv. Funct. Mater., 2003, 13, 85.

3. G. Li, V. Shrotriya, J. Huang, Y. Yao, T. Moriarty, K. Emery, Y. Yang, Nat. Mater. 2005, 4, 864-868.
4. J. Peet, J. Y. Kim, N. E. Coates, W. L. Ma, D. Moses, A. J. Heeger, G. C. Bazan, Nat. Mater. 2007, 6, 497-500.

5. Y. Liu, J. Zhao, Z. Li, C. Mu, W. Ma, H. Hu, K. Jiang, H. Lin, H. Ade, H. Yan, Nat. Commun. 2014, 5, 5293.

6. V. Vohra, K. Kawashima, T. Kakara, T. Koganezawa, I. Osaka, K. Takimiya, Nat. Photonics 2015, 9, 403-409.

7. J. Zhao, Y. Li, G. Yang, K. Jiang, H. Lin, H. Ade, W. Ma, H. Yan, Nat. Energy 2016, 1, 15027.

8. W. Jiang, L. Ye, X. Li, C. Xiao, F. Tan, W. Zhao, J. Hou, Z. Wang, Chem. Commun. 2014, 50, 1024-026.

9. Y. Lin, J. Wang, Z.-G. Zhang, H. Bai, Y. Li, D. Zhu, X. Zhan, Adv. Mater. 2015, $27,1170-174$

10. J. Zhang, Y. Li, J. Huang, H. Hu, G. Zhang, T. Ma, P. C. Y. Chow, H. Ade, D. Pan, H. Yan, J. Am. Chem. Soc. 2017, 139, 16092-16095.

11. Y. Cui, H. Yao, L. Hong, T. Zhang, Y. Xu, K. Xian, B. Gao, J. Qin, J. Zhang, Z. Wei, J. Hou, Adv. Mater. 2019, 31, 1808356.

12. L. Meng, Y. Zhang, X. Wan, C. Li, X. Zhang, Y. Wang, X. Ke, Z. Xiao, L. Ding, R. Xia, H,-L. Yip, Y. Cao, Y. Chen, Science 2018, 361, 1094-1098.

13. Q. An, F. Zhang, J. Zhang, W. Tang, Z. Deng, B. Hu, Energy Environ. Sci. 2016, 9, 281-322.

14. Q. An, X. Ma, J. Gao, F. Zhang, Science Bulletin 2019.

15. Z. Hu, F. Zhang, Q. An, M. Zhang, X. Ma, J. Wang, J. Zhang, J. Wang, ACS Energy Letters 2018, 3, 555-561.

16. X. Ma, W. Gao, J. Yu, Q. An, M. Zhang, Z. Hu, J. Wang, W. Tang, C. Yang, F. Zhang, Energy \& Environmental Science 2018, 11, 2134-2141.

17. B. Lim, J. Bloking, A. Ponec, M. D. McGehee, A. Sellinger, ACS Appl. Mater Interfaces 2014, 6, 6905-6913.

18. L. Lu, T. Xu, W. Chen, E. S. Landry, L. Yu, Nat. Photonics 2014, 8, 716722.

19. Y. Wang, H. Ohkita, H. Benten, S. Ito, Phys. Chem. Chem. Phys. 2015, 17, 27217-27224

20. L. Lu, W. Chen, T. Xu, L. Yu, Nat. Commun. 2015, 6, 7327.

21. F. Zhao, Y. Li, Z. Wang, Y. Yang, Z. Wang, G. He, J. Zhang, L. Jiang, T. Wang, Z. Wei, W. Ma, B. Li, A. Xia, Y. Li, C. Wang, Adv. Energy Mater 2017, 7, 1602552

22. R. Yu, S. Zhang, H. Yao, B. Guo, S. Li, H. Zhang, M. Zhang, J. Hou, Adv. Mater. 2017, 29, 1700437

23. N. Gasparini, X. Jiao, T. Heumueller, D. Baran, G. J. Matt, S. Fladischer, E. Spiecker, H. Ade, C. J. Brabec, T. Ameri, Nat. Energy 2016, 1, 16118.

24. J. Lee, V. Tamilavan, K. H. Rho, S. Keum, K. H. Park, D. Han, Y. K. Jung, C. Yang, Y. Jin, J.-W. Jang, J. H. Jeong, S. H. Park, Adv. Energy Mater. 2018, 8, 1702251 .

25. H. D. Kim, R. Shimizu, H. Ohkita, Chem. Lett. 2018, 47, 1059-1062.

26. N. Gasparini, S. Kahmann, M. Salvador, J. D. Perea, A. Sperlich, A. Baumann, N. Li, S. Rechberger, E. Spiecker, V. Dyakonov, G. Portale, M. A. Loi, C. J. Brabec, T. Ameri, Adv. Energy Mater. in press, DOI: 10.1002/aenm.201803394.

27. Y. Tamai, Y. Fan, V. O. Kim, K. Ziabrev, A. Rao, S. Barlow, S. R. Marder, R. H. Friend, S. M. Menke, ACS Nano 2017, 11, 12473-12481.

28. J. Guo, H. Ohkita, H. Benten, S. Ito, J. Am. Chem. Soc. 2010, 132, 61546164

29. J. Guo, H. Ohkita, S. Yokoya, H. Benten, S. Ito, J. Am. Chem. Soc. 2010, 132, 9631-9637.

30. J. Nelson, Phys. Rev. B 2003, 67, 155209

31. M. Tachiya, K. Seki, Phys. Rev. B 2010, 82, 085201.

32. G. Seybold, G. W. Wangenblast, Dyes Pig. 1989, 11, 303-317.

33. J. Huang, T. Goh, X. Li, M. Y. Sfeir, E. A. Bielinski, S. Tomasulo, M. L. Lee, N. Hazari, A. D. Taylor, Nat. Photonics 2013, 7, 479-485.

34. H. Ohkita, J. Kosaka, J. Guo, H. Benten, S. Ito, J. Photon. Energy 2011, 1, 011118.

35. Y. Wang, H. Ohkita, H. Benten, S. Ito, Phys. Chem. Chem. Phys. 2015, 17, 27217-27224.

36. H. Benten, T. Nishida, D. Mori, H. Xu, H. Ohkita, S. Ito, Energy Environ. Sci. 2016, 9, 135-140. 
37. Y. Tamai, K. Tsuda, H. Ohkita, H. Benten, S. Ito, Phys. Chem. Chem. Phys. 2014, 16, 20338-20346.

38. N. F. Mott, R. W. Gurney in Electronic Processes in lonic Crystals, Oxford: Oxford University Press, 1940.

39. D. Abbaszadeh, A. Kunz, G. A. H. Wetzelaer, J. J. Michels, N. I. Crăciun, K. Koynov, I. Lieberwirth, P. W. M. Blom, Nat. Mater. 2016, 15, 628-634.

40. S. Wang, S. Fabiano, S. Himmelberger, S. Puzinas, X. Crispin, A. Salleo, M. Berggren, Proc. Natl. Acad. Sci. USA 2015, 112, 10599-10604.

41. B. Tan, H. Pan, H. Li, M. L. Minus, B. M. Budhlall, M. J. Sobkowicz, J. Phys. Chem. C 2018, 122, 2918-2930.

42. B. Tang, J. Liu, X. Cao, Q. Zhao, X. Yu, S. Zheng, Y. Han, RSC Advances 2017, 7, 17913-17922.

43. M. E. Ziffer, S. B. Jo, Y. Liu, H. Zhong, J. C. Mohammed, J. S. Harrison, A. K. Jen, D. S. Ginger, J. Phys. Chem. C 2018, 122, 18860-18869.

44. H. Ohkita, Y. Tamai, H. Benten, S. Ito, IEEE J. Sel. Top. Quantum Electron. 2016, 22, 4100612. 


\section{ARTICLE}

Text for Table of Contents

Ternary beats binary in charge transport: hole transport is enhanced in PTB7-Th/PDCBT/PCBM ternary blend film compared to that in binary or neat original films. This is because ordering of PTB7-Th chains is improved in the ternary blend. As such, the enhanced hole transport gives an improved fill factor in the ternary blend solar cell.

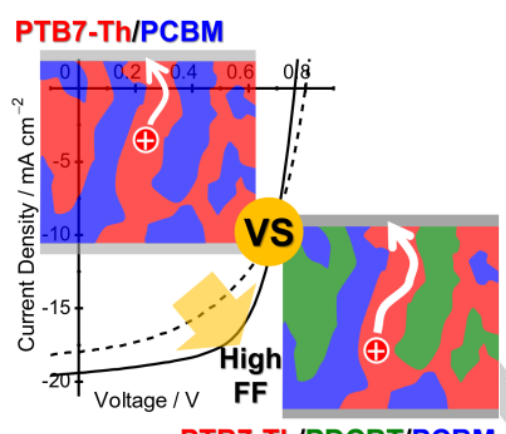

Koshiro Midori, Tomohiro Fukuhara, Yasunari Tamai, Hyung Do Kim, Hideo Ohkita*

Page No. - Page No.

Enhanced Hole Transport in Ternary Blend Polymer Solar Cells 